\title{
Mito e Religiosidade na Sociedade Líquida
}

\author{
Edival Saraiva de Oliveira Neto ${ }^{1}$; Anna Christina Farias de Carvalho ${ }^{2}$
}

\begin{abstract}
Resumo: O conceito de Zigmund Bauman $(2001)^{3}$ acerca da Modernidade, apresenta características como individualidade, consumismo, liquidez, fluidez, apontando para uma sociedade onde tudo se resume em "bens consumíveis", e por extensão também os "bens de salvação", lembrando Bourdieu (2005) incluindo as relações afetivas, tudo ao alcance do click de um mouse. Nesse sentido, a "fluidez" característica do homem pós-moderno faz com que as relações sociais de establishment não tenham a concretude de outrora, pois "nada é eterno" ou duradouro, nem a religião, nem as relações afetivas, a vida profissional e familiar, são aspectos do social impregnados dessa "liquidez". Nesse contexto, nossa pesquisa em andamento, objetiva analisar na obra de Z. Bauman como o homem pós-moderno percebe Deus, as formas religiosas e o mito. Diante dessas considerações, pergunta-se: há em Bauman uma teoria completa da religião? A metodologia utilizada será qualitativa, com ênfase na análise textual e fontes bibliográficas e eletrônicas. Pretendemos com essa investigação compreender o pensamento baumaniano sobre a modernidade, que segundo Bauman (1998) interfere profundamente na religião e cujo aspecto permanente é a "liquidez", apontando para uma mudança sociocultural que submerge a estrutura fixa e emerge uma estrutura extremamente móvel.
\end{abstract}

Palavras - chave: Modernidade. Religião. Bauman.

\section{Myth and Religiousity in Liquid Society}

\begin{abstract}
Zigmund Bauman's (2001) concept of Modernity presents characteristics such as individuality, consumerism, liquidity, fluidity, pointing to a society where everything is summed up as "consumables", and by extension also the "goods of salvation", remembering Bourdieu (2005) including affective relationships, all within reach of the click of a mouse. In this sense, the "fluidity" characteristic of postmodern man causes the social relations of establishment not to have the concreteness of the past, since "nothing is eternal" or lasting, neither religion nor affective relations, professional life and Familiar aspects of society are impregnated with this "liquidity". In this context, our ongoing research aims to analyze in the work of Z. Bauman how the postmodern man perceives God, the religious forms and the myth. In view of these considerations, one wonders: is there in Bauman a complete theory of religion? The methodology used will be qualitative, with emphasis on textual analysis and bibliographic and electronic sources. We intend to understand Bauman's thinking about modernity, which according to Bauman (1998) deeply interferes with religion and whose permanent aspect is "liquidity", pointing to a sociocultural change that submerges the fixed structure and emerges an extremely mobile structure.
\end{abstract}

Keywords: Modernity. Religion. Bauman.

\footnotetext{
${ }^{1}$ Graduando em Ciências Sociais pela Universidade Regional do Cariri - URCA. Pesquisador Voluntário. Pesquisador do Núcleo de Estudos em Ciência, Religiosidade e Filosofia - NECEF/URCA.

${ }^{2}$ Doutora em Sociologia pela Universidade Federal da Paraíba - UFPB. Professora Aposentada da Universidade Regional do Cariri - URCA. Pós-Doutora em Letras pela Universidade Federal da Paraíba. Pesquisadora do Núcleo de Estudos em Ciência, Religiosidade e Filosofia - NECEF/URCA. Assessora de Cultura e Extensão da Pró-Reitoria de Extensão da URCA. E-mail: anna_crica@hotmail.com;

${ }^{3} \mathrm{O}$ sociólogo e filósofo polonês Zygmunt Bauman, criador do conceito de modernidade líquida e considerado um dos principais intelectuais do século XX, morreu em Leeds, na Inglaterra, aos 91 anos, no dia 09 de janeiro de 2017.
} 
Id on Line Revista Multidisciplinar e de Psicologia

Id on Line Multidisciplinary and Psycology Journal

\section{Introdução}

Ao longo do Século XX e início do Século XXI, observamos dois fenômenos fundamentais para analisar a estrutura das relações da religião: diversidade e transformações. Tais fenômenos são importantes para se compreender um campo religioso de pluralismo galopante.

A modernidade pode ser apontada como um campo religioso de transformações crescentes, que engloba variadas expressões de religiosidade e onde está visível a transição de um campo religioso, até então hegemônico, ocupado pela Igreja Católica Romanizada, para uma diversidade de práticas religiosas. Tomando por empréstimo a expressão de Berger, estamos em plena era da "dessecularizção ${ }^{1}$." Outro aspecto que nos chama atenção, além do reavivamento religioso da sociedade, é a forma diferenciada de se praticar e vivenciar a religiosidade, com base em contornos menos institucionalizados, mais individualizados. O surgimento e a expansão de novas expressões religiosas vão desde a ascensão das igrejas pentecostais e neopentecostais até os novos movimentos religiosos, englobados com a denominação de Nova Era.

Autores como Berger (2001), Giddens (1991), Bauman (2001), entre outros, analisam que, paralelamente às mudanças sociais da modernidade, da pós-modernidade, da modernidade líquida etc., acompanha um processo de modernização do campo religioso, com transformações significativas na organização das instituições religiosas, e um pluralismo crescente nos modos e nas práticas de se crer e praticar a fé. Isso, contrariando as conjecturas dos cientistas sociais do Século XIX e início do Século XX, que projetavam em suas análises o ocaso da religião nas modernas sociedades capitalistas. Nesse sentido, os objetivos de nossa pesquisa, inicialmente, são: Geral, compreender, por meio da análise da Sociologia de Bauman, o estado atual do campo sociológico em suas relações com a religião;

Específicos, compreender a natureza social da sociologia de Bauman; analisar a fragmentação do indivíduo e sua relação com a religião, através dos escritos baumanianos; caracterizar o sagrado (Deus) na sociedade descartável conceituada por Bauman; relacionar religião e consumismo; identificar práticas do sagrado na sociedade líquida.

\footnotetext{
${ }^{1}$ A dessecularização do mundo: uma visão global, 2001. p. 9-33 
A partir de nosso estudo, pretendemos responder essas e outras indagações próprias do homem moderno em sua solidão cibernética. Entendemos, como Feuerbch (1977) a religião como sendo um aspecto do ser humano extremamente importante:

\begin{abstract}
Nessa perspectiva podemos dizer que religião é, por excelência, uma porta para a transcendência. E o mais importante aqui consiste em compreender que religião é -invenção humana. Feuerbach, por meio de sua obra - A Essência do Cristianismo, trabalhando a dimensão antropológica da religião, nos diz categoricamente que - 'o homem é o início da religião, o homem é o meio da religião, o homem é o fim da religião' (FEUERBCH, 1997, p. 223 Apud TOLOVI, 2011, p.124).
\end{abstract}

É nesse sentido que justificamos nosso estudo. Procurar entender a complexa relação desse homem fragmentado do mundo moderno em busca de sua transcendência.

Nesse contexto, a contemporaneidade líquida desnudada por Bauman, conforme referido, não traduz solidez ou concretude nos mais variados aspectos humanísticos emocionais, ideológicos, religiosos, entre outros. Com o avanço da globalização, há uma hipervalorização no "ter" o que acarreta um alto nível de consumismo. Neste palco de mudanças aceleradas, a instabilidade e a flexibilidade do indivíduo, desta decorrente, tornou o indivíduo refém do mercado, do marketing da espetacularização e publicização da vida privada, especialmente via redes sociais. É a exacerbação do Pan- óptico de Jeremy Bentham (1785) e do Big Brother de George Owen em 1984 (1949). Como entender a religião nessa sociedade do descartável? Deus também se tornou descartável ou transmudou em outra(s) forma(s) de explicar a cosmovisão das diversas culturas e do indivíduo, à procura de rastros do sagrado na sociedade líquida.

\title{
Problematização Teórica
}

Como articular o conhecimento científico, sociológico sobre a sociedade com o conhecimento da vida cotidiana, do senso comum? Eis uma das pretensões de Zygmunt Bauman em suas análises sobre a modernidade líquida, conceito cunhado por ele para contrapor-se ao seu contrário "sólido":

Diferentemente da sociedade moderna anterior, que chamo de "modernidade sólida", que também tratava sempre de desmontar a realidade herdada, a de agora não o faz com uma perspectiva de longa duração, com a intenção de torná-la melhor e novamente sólida. Tudo está agora sendo permanentemente desmontado, mas sem 


\begin{abstract}
perspectiva de alguma permanência. Tudo é temporário. É por isso que sugeri a metáfora da "liquidez" para caracterizar o estado da sociedade moderna: como os líquidos, ela caracteriza-se pela incapacidade de manter a forma. Nossas instituições, quadros de referência, estilos de vida, crenças e convicções mudam antes que tenham tempo de se solidificar em costumes, hábitos e verdades "auto evidentes”. Sem dúvida a vida moderna foi desde o início "desenraizadora", "derretia os sólidos e profanava os sagrados", como os jovens Marx e Engels notaram. Mas enquanto no passado isso era feito para ser novamente "re-enraizado", agora todas as coisas - empregos, relacionamentos, know-hows etc. - tendem a permanecer em fluxo, voláteis, desreguladas, flexíveis. A nossa é uma era, portanto, que se caracteriza não tanto por quebrar as rotinas e subverter as tradições, mas por evitar que padrões de conduta se congelem em rotinas e tradições. (PALLARES-BURKE, 2004, p. 321).
\end{abstract}

Nesse contexto, o título da obra (Modernidade Líquida, 2001) decorre da modernidade da sociedade que avança em vários sentidos, porém, questionável em suas atitudes e o seu contexto enquanto sociedade. A liquidez, a qual Bauman propõe vem do fato que os líquidos não têm uma forma, ou seja, são fluídos que se moldam conforme o recipiente nos quais estão contidos, diferentemente dos sólidos que são rígidos e precisam sofrer uma tensão de forças para moldar-se a novas formas.

E a religião? De acordo com o sociólogo polonês:

\footnotetext{
A religião, na verdade, é a consciência da insuficiência humana, é vivida na admissão da fraqueza... A mensagem invariável do culto religioso é: 'do finitoao infinito, a distância é sempre infinita...' (...) nós deparamos com dois caminhos inconciliáveis de aceitar o mundo e a nossa posição nele, nenhum dos quais pode ufanar-se de ser mais racional do que o outro...Uma vez feita, qualquer escolha impõe critérios de julgamento que, infalivelmente, a apóiam numa lógica circular: se não há nenhum Deus, só critérios empíricos devem guiar-nos o pensamento, e critérios empíricos não conduzem a Deus, se Deus existe ele nos dá pistas sobre como perceber Sua mão no curso dos acontecimentos, e com a ajuda dessas pistas reconhecemos a razão divina do que quer que aconteça. (BAUMAN, p.209, 1998)
}

O termo "secularização" engloba vários componentes. Geralmente se compreende como a "vida sem Deus e sem religião". Isto porque no passado eram esses componentes a ditar a visão de mundo, a auto compreensão e definição humana e a orientação do agir. A tentativa de estabelecer um binômio ou oposição como Deus-mundo, fé-razão, ciência-crença, não são verdadeiros deste período.

Na verdade, a secularização não quer eliminar Deus e a religião, mas simplesmente fazer que ocupem o seu novo espaço dentro do novo horizonte de compreensão. $\mathrm{Na}$ visão e compreensão do homem moderno, o centro do universo passa a ser ele mesmo. Deus e o mundo 
Id on Line Revista Multidisciplinar e de Psicologia

Id on Line Multidisciplinary and Psycology Journal

passam para um segundo ou terceiro plano (CARVALHO, NASCIMENTO e OLIVEIRA, 2016).

É nesse sentido que estamos problematizando nosso trabalho a partir das seguintes indagações: Será a religião um ponto sólido na modernidade líquida? É possível discutir semelhanças entre o consumismo e a religião na concepção baumaniana? Como conceituar, na modernidade líquida, a busca pela transcendência na religião?

É nesse sentido que justificamos nosso estudo. Procurar entender a complexa relação desse homem fragmentado do mundo moderno em busca de sua transcendência.

Nesse contexto, a contemporaneidade líquida desnudada por Bauman, conforme referido, não traduz solidez ou concretude nos mais variados aspectos humanísticos emocionais, ideológicos, religiosos, entre outros. Com o avanço da globalização, há uma hipervalorização no "ter" o que acarreta um alto nível de consumismo. Neste palco de mudanças aceleradas, a instabilidade e a flexibilidade do indivíduo, desta decorrente, tornou o indivíduo refém do mercado, do marketing da espetacularização e publicização da vida privada, via redes sociais. É a exarcebação do Pan- óptico de Jeremy Bentham (1785) e do Big Brother de George Owen em 1984 (1949). Como entender a religião nessa sociedade do descartável? Deus também tornou-se descartável ou transmudou-se em outra(s) forma(s) de explicar a cosmovisão das diversas culturas e do indivíduo? Nesse contexto, estamos, em nossa pesauisa, à procura de rastros do sagrado na sociedade líquida.

\section{Procedimentos Metodológicos}

Nesta pesquisa de natureza teórica, pretende-se "rastrear", através da pesquisa bibliográfica, eletrônica e da análise textual, nos escritos de Bauman, a noção de religião na sociedade da Modernidade Líquida, caracterizada, segundo o autor, pela individualidade, consumismo, liquidez, fluidez, onde tudo se resume em "bens consumíveis" e pelo descarte, inclusive as relações sociais e por extensão, a religião.

Gil (2008) aponta que de acordo com os objetivos da pesquisa, a pesquisa exploratória proporcionar maior familiaridade com o problema (explicitá-lo). Pode envolver levantamento bibliográfico, entrevistas com pessoas experientes no problema pesquisado. Geralmente, 
Id on Line Revista Multidisciplinar e de Psicologia

Id on Line Multidisciplinary and Psycology Journal

assume a forma de pesquisa bibliográfica e estudo de caso. Em seus aspectos técnicos é desenvolvida com base em material já elaborado, constituído principalmente de livros e artigos científicos.

Sendo uma pesquisa qualitativa, utilizaremos a análise textual que no entender de Gil (2008) consiste em buscar informações a respeito do autor do texto, verificar o vocabulário, entre outros, podendo ser finalizada com uma esquematização do texto, tendo como finalidade apresentar uma visão de conjunto da unidade. É necessário o leitor relembrar que análise significa estudar um todo, dividindo em partes, interpretando cada uma delas, para a compreensão do todo. Quando se faz análise de texto, penetramos na ideia e no pensamento do autor que originou o texto. Para que o estudo do texto seja completo, temos que decompô-lo em partes e, ao fazê-lo, estamos efetuando sua análise.

\section{Considerações Finais}

Salientamos que o estudo de Bauman é nosso ponto de partida para uma descrição mais densa de uma teoria própria da religiosidade na contemporaneidade. Pretendemos ampliar, em uma segunda etapa, para uma pesquisa de campo com alunos do Curso de Ciências Sociais da URCA, onde buscaremos apreender as percepções desses alunos em relação a religião na Modernidade Líquida e assim contribuirmos para as discussões acerca da Sociologia da Religião.

\section{Referências}

BAUMAN, Zigmunt. 2001. Modernidade Líquida. Rio de Janeiro: ed. Zahar.

O Mal Estar da pós - modernidade. Rio de Janeiro: Jorge Zahar, 1998.

BERGER, Peter. A dessecularização do mundo: uma visão global, 2001. Religião e Sociedade, Rio de Janeiro, 2000. n. 21, v.1, p. 9-33.

CARVALHO, A.C.F.; NASCIMENTO, M.C.D.; OLIVEIRA, G.F. Textos religiosos e práticas cotidianas: leitura de aspectos simbólicos da Irmandade de Penitentes Peregrinos Públicos Juazeiro do Norte-CE. Id on Line Revista de Psicologia, Set-Out, vol.10, n.31, p. 221-240, 2016. 
GIDDENS, Anthony. 1991. 2a . Reimpressão. As Consequências da Modernidade. São Paulo:ed. UNESP.

GIL, Antonio Carlos. Como elaborar projetos de pesquisa. 4. ed. São Paulo: Atlas, 2008. PALLARES-BURKE, Maria Lúcia. Entrevista com Zygmunt Bauman. Tempo Social, São Paulo:USP, Jun. 2004, p. 09-23.

TOLOVI, Carlos Alberto. Mito, religião e organização social. Pensar - Revista Eletrônica da Faje, 2011, v. 2, n. 1.

Como citar este artigo (Formato ABNT):

OLIVEIRA NETO, E.S.; CARVALHO, A.C.F. Mito e Religiosidade na Sociedade Líquida. Id on Line Revista Multidisciplinar e de Psicologia, Fevereiro de 2017, vol.11, n.34, p. 39-45. ISSN: 1981-1179.

Recebido: 08/02/2017

Aceito: 10/02/2017 